\title{
Body iron metabolism and pathophysiology of iron overload
}

\author{
Yutaka Kohgo · Katsuya Ikuta · Takaaki Ohtake • \\ Yoshihiro Torimoto $\cdot$ Junji Kato
}

Received: 30 April 2008/Accepted: 2 June 2008/Published online: 2 July 2008

(C) The Japanese Society of Hematology 2008

\begin{abstract}
Iron is an essential metal for the body, while excess iron accumulation causes organ dysfunction through the production of reactive oxygen species. There is a sophisticated balance of body iron metabolism of storage and transport, which is regulated by several factors including the newly identified peptide hepcidin. As there is no passive excretory mechanism of iron, iron is easily accumulated when exogenous iron is loaded by hereditary factors, repeated transfusions, and other diseased conditions. The free irons, non-transferrin-bound iron, and labile plasma iron in the circulation, and the labile iron pool within the cells, are responsible for iron toxicity. The characteristic features of advanced iron overload are failure of vital organs such as liver and heart in addition to endocrine dysfunctions. For the estimation of body iron, there are direct and indirect methods available. Serum ferritin is the most convenient and widely available modality, even though its specificity is sometimes problematic. Recently, new physical detection methods using magnetic resonance imaging and superconducting quantum interference devices have become available to estimate iron concentration in liver and myocardium. The widely used application of iron chelators with high compliance will
\end{abstract}

Y. Kohgo $(\bowtie) \cdot$ K. Ikuta $\cdot$ T. Ohtake $\cdot$ Y. Torimoto

Division of Gastroenterology and Hematology/Oncology,

Department of Medicine, Asahikawa Medical College,

Asahikawa, Japan

e-mail: yskohgo@aol.com

J. Kato

Fourth Department of Internal Medicine,

Sapporo Medical University, Sapporo, Japan resolve the problems of organ dysfunction by excess iron and improve patient outcomes.

Keywords Hemochromatosis · Hepcidin .

Iron metabolism · Iron overload .

Non-transferrin-bound iron (NTBI)

\section{Introduction}

Iron is an essential metal for hemoglobin synthesis of erythrocytes, oxidation-reduction reactions, and cellular proliferation, whereas excess iron accumulation causes organ dysfunction through the production of reactive oxygen species (ROS). The total amount of body iron is approximately 3-4 g, two-thirds of which is composed of red blood cell (RBC) iron and recycled iron by RBC destruction; the remainder is stored in ferritin/hemosiderin, while only $1-2 \mathrm{mg}$ of iron are absorbed in the intestinal tract and circulated in the blood [1]. Body iron metabolism is a semi-closed system, and is critically regulated by several factors including the newly identified peptide hepcidin. In the circulation, iron is usually bound to transferrin (Tf), and most of the Tf-bound iron is utilized for bone marrow erythropoiesis [1]. As there is no active mechanism to excrete iron from the body, a progressive accumulation of body iron easily occurs as a result of long-term transfusions in patients with anemia of genetic disorders such as thalassemia, sickle cell disease (SCD), and Diamond Blackfan syndrome, and of bone-marrow failures such as aplastic anemia (AA) and myelodysplastic syndromes (MDS). In order to consider pathophysiological mechanisms of organ injury by iron overload, an understanding of molecular mechanisms of body iron metabolism is essential. 
Table 1 Molecules involved in body iron metabolism

\begin{tabular}{l} 
Molecules for intestinal iron absorption \\
Divalent metal transporter 1 (DMT1) \\
Duodenal cytochrome $b$ (Dcytb) \\
Heme carrier protein (HCP) \\
Hemeoxygenase-1 \\
Ferroportin \\
Hephaestin \\
Transferrin \\
Molecules for bone marrow iron uptake \\
Transferrin receptor 1 \\
Transferrin \\
Molecules for reutilization of senescent red blood cells \\
Hemeoxygenase-1 \\
Ferroportin \\
Transferrin \\
Molecules for hepatic iron storage \\
Ferritin \\
Hemosiderin \\
Transferrin \\
Transferrin receptor 1 \\
Transferrin receptor 2 \\
Non-transferrin-bound iron \\
HFE \\
Divalent metal transporter 1 \\
Hemoju \\
(Unknown erythroid regulator?) \\
\hline
\end{tabular}

\section{Molecular mechanisms of body iron metabolism}

Table 1 shows a list of molecules involved in body iron metabolism, categorized as functions including intestinal absorption, erythroid iron uptake, reutilization of senescent $\mathrm{RBCs}$, hepatic iron storage, and systemic regulation.

\subsection{Intestinal iron absorption}

Ingested iron is classified as non-heme iron and heme iron. Non-heme iron derived from plants is mainly composed of inorganic ferric $\mathrm{Fe}(\mathrm{III})$ iron, and is absorbed into enterocytes through the divalent metal transporter 1 (DMT1) after reduction of $\mathrm{Fe}$ (III) to $\mathrm{Fe}$ (II) by duodenal cytochrome $b$ [2, 3]. In contrast, heme-iron derived from meat is absorbed through a heme carrier protein into enterocytes, where it is degraded by hemeoxygenase-1 (HO-1). Iron within enterocytes is then transferred from the luminal to the vascular site of the cell, and released into the circulation via the metal transporter, ferroportin in the form of $\mathrm{Fe}(\mathrm{II})$. Excreted $\mathrm{Fe}(\mathrm{II})$ is thereafter oxidized to $\mathrm{Fe}(\mathrm{III})$ by hephaestin, a homolog of ceruloplasmin, and the resulting ferric iron is bound to serum $\mathrm{Tf}$ [4].

2.2 Red blood cell iron reutilization in the reticuloendothelial system (RES) and iron load by blood transfusion

The average life span of circulating RBCs is approximately 120 days, indicating that $20 \mathrm{mg}$ of iron derived from $20 \mathrm{ml}$ of RBCs are processed by RES/macrophages on a daily basis. Within macrophages, heme derived from phagocytized RBCs is catabolized by HO- 1 , and free iron is released.

Intra-cellular iron is released into the circulation via ferroportin, and the iron is donated to $\mathrm{Tf}$ and reutilized for bone marrow erythropoiesis.

In patients with genetic anemias and bone marrow failures, regular transfusion is required in order to overcome the intractable symptoms. Transfused RBCs are taken up and degraded by RES/macrophages, in which the recycled iron is overloaded and the excess iron saturates the binding capacity of Tf. This excess iron appears in the circulation as a form of non-Tf-bound iron (NTBI) [1, 5], and causes organ dysfunction by the production of ROS. One milliliter of blood contains approximately $0.5 \mathrm{mg}$ of iron, and there is no active mechanism for excretion of this excess iron. In Japan, one unit of blood corresponds to $200 \mathrm{ml}$ of whole blood or $140 \mathrm{ml}$ of concentrated RBCs, both of which contain approximately $100 \mathrm{mg}$ of iron. As the critical level of iron overload at which organ dysfunction occurs in the liver is approximately $7 \mathrm{mg} / \mathrm{g}$ dry liver weight [6], according to the formula derived by Angelucci [body iron accumulation $(\mathrm{mg} / \mathrm{kg})=$ liver iron concentration (LIC; $\mathrm{mg} /$ $\mathrm{g}$ dry weight $\times 10.6$ )] [7], only 40 Japanese units of transfusion are required to reach this level.

\subsection{Iron uptake and utilization in liver}

The liver is a major storage organ of iron, in which excess iron is stored as ferritin and hemosiderin. In addition to these proteins, an additional fraction of free iron is present in the form of the labile iron pool (LIP) within cells. The LIP is biologically active in intracellular metabolism via oxidation-reduction reactions, cell proliferation, and cell signaling, but is toxic if present in excess. As shown in Fig. 1, hepatocytes have essentially two pathways for uptake of iron from the circulation: Tf-bound iron $\left(\mathrm{Fe}_{2}-\mathrm{Tf}\right)$ at physiological iron concentrations, and NTBI in iron overload conditions [3].

Concerning the uptake of $\mathrm{Fe}_{2}$ - $\mathrm{Tf}$, there are three pathways involved: two are dependent on and one is independent of transferrin receptor (TfR) recycling. 


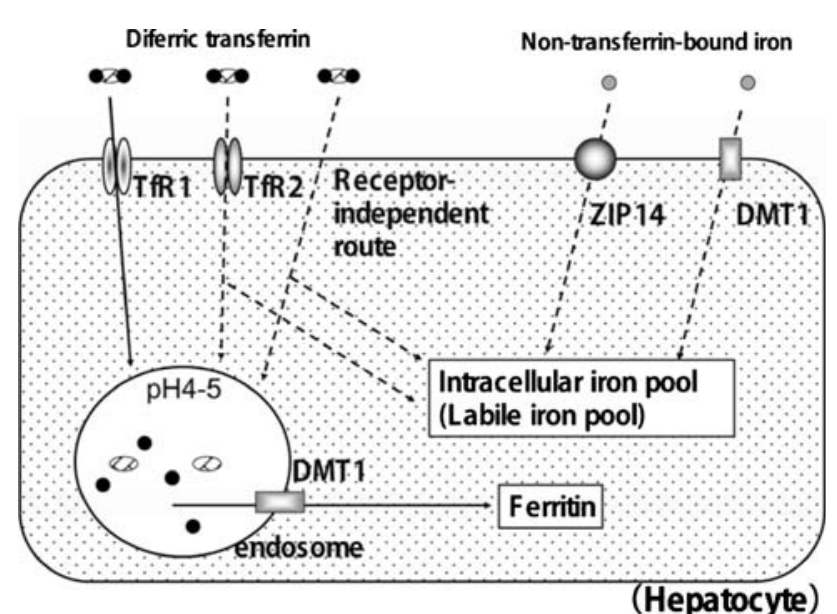

Fig. 1 Routes for iron uptake by hepatocytes. Hepatocytes have several pathways for iron uptake from the circulation. Concerning uptake of Tf-bound iron $\left(\mathrm{Fe}_{2}-\mathrm{Tf}\right)$ at physiological concentrations, there are three pathways involving TfR1, TfR2, and TfR-independent mechanisms. The pathway via TfR 1 is a classical one and is well elucidated. When serum $\mathrm{Fe}_{2}$-Tf binds to TfR1, the $\mathrm{Fe}_{2} \mathrm{Tf}-\mathrm{TfR} 1$ complex is internalized by endocytosis, and iron is released within the endosome when endosomal $\mathrm{pH}$ is acidic. The resulting apotransferrinTfR1 complex is then recycled back to the cell surface for reutilization. Released iron into the endosome is transferred to the cytoplasm by DMT1; the resulting cytoplasmic free iron is used for iron-related biological functions, and the rest of the iron is stored as ferritin. In addition to TfR1, TfR2 and the mechanism that is independent of TfR 1 and TfR2, are also considered to be important routes for iron uptake in hepatocytes, but the details of these routes remain to be elucidated. Concerning the hepatic uptake of NTBI, which is present in the serum during conditions of iron overload, DMT1 and ZIP14 are considered to be involved

Transferrin receptor 1 (TfR1) is a classical functional receptor, expressed highly in erythroblasts, but less so in hepatocytes. When serum $\mathrm{Fe}_{2}$-Tf binds to TfR1, $\mathrm{Fe}_{2}$-Tf is internalized by endocytosis. Internalized $\mathrm{Fe}_{2} \mathrm{Tf}-\mathrm{TfR} 1$ complexes within the endosome release iron when endosomal $\mathrm{pH}$ is acidified. The resulting apotransferrin-TfR1 complex is then recycled back to the cell surface for reutilization. Transferrin receptor 2 (TfR2), a new homolog of TfR1, is ubiquitously expressed on hepatocyte surfaces and possesses a similar mechanism of recycling, but the binding affinity is rather weak: the functional role of TfR2 for cellular iron uptake is still obscured. In hepatocytes, there is another $\mathrm{Fe}_{2}$ - $\mathrm{Tf}$ uptake mechanism that is independent of TfR recycling, which is also considered to be important [8].

In iron-overloaded conditions, NTBI appears in the circulation and is taken up through two molecules such as DMT1 and ZIP14 on hepatocytes [9].

\subsection{Bone marrow iron metabolism and erythropoiesis}

Bone marrow erythroblasts require large amounts of iron for hemoglobin synthesis. TfR1 is strongly expressed in erythroblasts and functions as the uptake system of extracellular $\mathrm{Fe}_{2}$-Tf. Within erythroblasts, iron is transferred to mitochondria and is incorporated into the center of the heme ring, which is synthesized by condensation of $\delta$ aminolevulinic acid, a product made by erythroid $\delta$-aminolevulinic acid synthase (eALAS). It is noteworthy that the synthesis of eALAS is also regulated by an ironresponsive-element binding protein (IRP) as well as TfR1 [10]. It is well known that genetic abnormalities of this pathway cause the phenotype of ringed sideroblastic anemias [11].

\subsection{Systemic regulation of body iron metabolism}

It has been postulated for a long time that a soluble factor acts to synchronize body iron metabolism between different organs. Recently, a basic peptide called hepcidin, an antimicrobial purified from urine, was found to have this role [12]. Hepcidin is considered to be a negative regulator that inhibits both intestinal iron absorption and reticulo-endothelial iron release. It is mainly synthesized in the liver, in which production is enhanced during iron overload and inflammation [13]. In some patients with genetic hemochromatosis, an abnormality of hepcidin gene has been reported. In these patients, hepcidin production was suppressed and iron absorption increased [14]. Furthermore, hepcidin expression is also down-regulated even in patients without a genetic abnormality of hepcidin. These reports strongly suggest that hepcidin plays an important role in tissue iron deposition in many iron-overloaded conditions including HFE hemochromatosis [15]. Currently, several additional molecules such as TfR2 and hemojuvelin (HJV) are also known to be involved in its regulation [16]. Furthermore, it is becoming clear that there is a role for hepcidin even in secondary iron overload. In a mouse model of $\beta$-thalassemia, representing ineffective erythropoiesis, there is an upregulation of hepcidin and a down-regulation of ferroportin, explaining how hepcidin also contributes to the formation of secondary hemochromatosis associated with ineffective erythropoiesis [17].

\section{Forms of iron in serum and tissue}

As free iron is extremely toxic to cells, the body has a number of protective mechanisms with which to bind iron in various tissue compartments. In serum, iron is usually bound to Tf, but some is present as NTBI when iron concentration exceeds the iron binding capacity of plasma Tf. It is also noted that ferritin is present in serum, although its biological role in iron transport is unclear. 
3.1 Iron in plasma: Tf-bound iron and non-Tf-bound iron (NTBI)

It is well known that plasma $\mathrm{Tf}$ is capable of binding and transporting ferric iron to cells via TfRs. The binding capacity of $\mathrm{Tf}$ to inorganic iron is very strong, and this characteristic behavior prevents iron from existing in its free form under normal physiological conditions. As the Tf saturation in normal physiological conditions is up to $35 \%$, this suggests that there is sufficient capacity to prevent the release of free toxic iron into the circulation [18]. However, when the iron binding capacity of $\mathrm{Tf}$ is saturated in the iron-overloaded state, an additional iron compartment NTBI, appears in the circulation. This compartment is biologically more toxic than Tf-bound iron. Among the NTBI fractions, labile plasma iron (LPI) is the most toxic. Unlike Tf-bound iron, the cellular uptake of NTBI is not dependent on the TfR, and therefore the resulting iron is diffusely distributed throughout the organs, independent of the presence of the TfR [5, 19]. Unlike serum iron, TIBC and percent-Tf-saturation measurements, the inter-institutional difference of NTBI and LPI measurements are too great and these parameters have not been standardized.

\subsection{Iron in tissue: tissue ferritin and labile iron pool} (LIP)

Within cells, iron is stored in the proteins ferritin or hemosiderin. Ferritin is a cytoplasmic protein consisting of 25 heterodimeric subunits of $\mathrm{H}$ and $\mathrm{L}$ that stores iron as ferric hydroxide phosphate in a controlled manner. Each molecule can store up to $4,500 \mathrm{Fe}$ (III) within the protein shell [20], and release greater quantities of iron when the body is iron deficient. Most ferritin is present in liver, spleen, and bone marrow, and a trace amount is found in the blood as serum ferritin. It is noteworthy that the synthesis of ferritin is post-transcriptionally regulated by the cytoplasmic transacting factor IRP. IRP activates ferritin synthesis when iron is excess in the cell [21]. This adaptive response is important for preventing cells from free iron toxicity.

In addition to ferritin iron, LIP is present within cells in order to facilitate biological actions involving iron atoms, and can become cytotoxic or carcinogenic when the concentration exceeds the protective capacity of ferritin. Most of the LIP is free ferric iron bound to citrate or adenosine diphosphate, and a small amount of LIP is reduced to ferrous iron, which is responsible for oxidation-reduction reactions and the Fenton reaction. Iron toxicity is developed thorough the production of ROS.

\subsection{Serum ferritin}

In 1972, Jacobs et al. [22, 23] in the UK reported that ferritin was also present in serum, although its amount was very low. By quantitative phlebotomy, it was found that serum ferritin (SF) correlated with total body iron stores. Although it is still not clear how SF is produced, it is the most convenient laboratory test available to estimate body iron stores at the present time. However, the level of SF is also affected by acute and chronic inflammation and infections. Therefore, data should be interpreted carefully when using SF as a biological marker for evaluation of body iron stores, as shown in Table 2. There is a difference between the standard values of SF concentration in males and females (normal range 10-220 $\mu \mathrm{g} / \mathrm{L}$ in males; 10$85 \mu \mathrm{g} / \mathrm{L}$ in females). It is clear that low SF values less than

Table 2 Considerations needed to use serum ferritin as a biological marker for the evaluation of body iron store

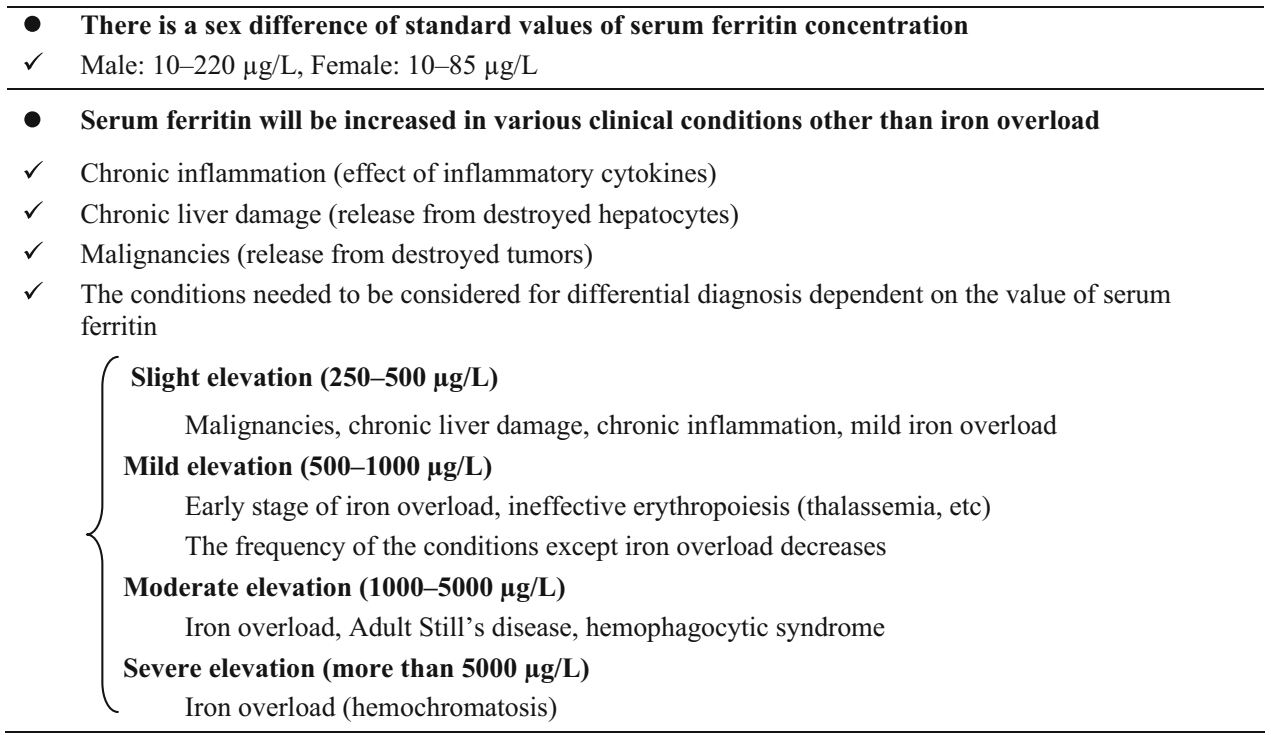


$12 \mu \mathrm{g} / \mathrm{L}$ are usually representative of body iron deficiency. On other hand, patients with SF levels that are higher than the normal range may be indicative of conditions such as iron overload, inflammation, collagen disease, malignancy, and hepatic diseases [24]. This characteristic feature of the $\mathrm{SF}$ assay is considered to be a disadvantage for monitoring iron overload. Especially in Japan, the significance of SF as an inflammation marker has been over-stressed because there are few patients with hereditary hemochromatosis showing significantly high values of more than a couple of thousand or ten thousand microgram per liter.

Systemic measurements of SF in various diseases were conducted mainly in the late 1970s, just after the development of this assay, and it was found that AA and sideroblastic anemia patients who had received blood transfusions had SF levels of more than $1,000 \mu \mathrm{g} / \mathrm{L}$, whereas patients without transfusions had lower levels. These old data have suggested previously that anemic patients who had ineffective erythropoiesis without transfusion support could maintain their SF levels at values less than $1,000 \mu \mathrm{g} / \mathrm{L}$, even though adaptive increases in intestinal iron absorption were noted [25]. Therefore, the interpretation of the value of SF for the assessment of body iron status is simplified if other clinical conditions such as inflammation and malignancy are excluded by other modalities. The clinical studies concerning the relationship between blood transfusion and SF have been conducted mainly in the Europe and US, showing that there is a clearcut positive correlation between the amount of chronic blood transfusion and the elevation of SF in patients with $\beta$-thalassemia [26, 27]. Furthermore, the concentration of heart iron is increased when SF levels become greater than $1,800 \mu \mathrm{g} / \mathrm{L}$, and the prevalence of cardiac events is significantly increased when SF levels are more than $2,500 \mu \mathrm{g} / \mathrm{L}[6,28]$. Similar results concerning the relationship between SF and organ dysfunction of liver and heart were shown in a Japanese retrospective study in transfusion-dependent patients with bone-marrow-failure syndromes [29]. In this study, $90 \%$ of patients with either cardiac or hepatic complications had high SF levels of more than 1,000 $\mu \mathrm{g} / \mathrm{L}$. Coincidentally, this level of SF also represents the threshold of the target value at which iron chelation therapy should be initiated in patients with transfusion iron overload, according to the guidelines of the International MDS Symposium [30].

\section{Measurement of body iron stores: comparison with serum ferritin}

Direct and indirect methods are available for the estimation of body iron. As previously mentioned, the measurement of $\mathrm{SF}$ is the most convenient and cost-effective technique,

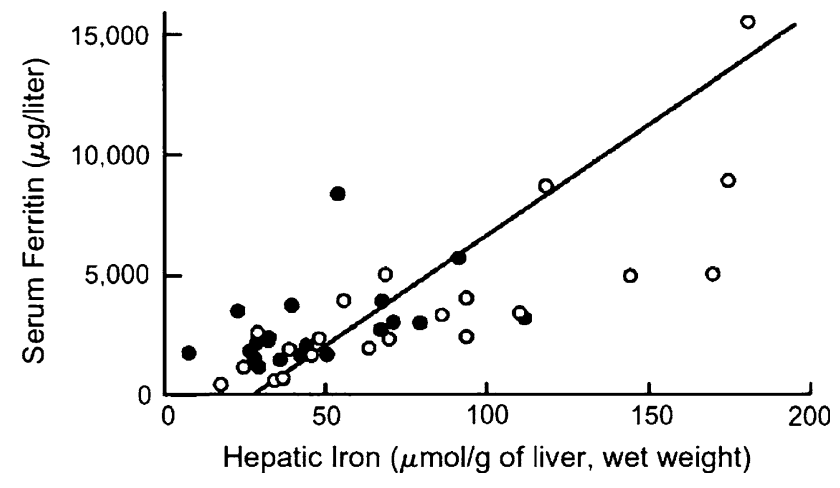

Fig. 2 Comparison of hepatic iron and serum ferritin concentrations. Indirect estimation is compared with the reference method, based on the direct measurement of hepatic iron levels by chemical analysis or magnetic-susceptibility studies. Open circles denote the values at the start of the trial (before deferiprone therapy), and solid circles the values at the time of the final analysis. The diagonal line denotes the simple linear least-squares regression between the two variables. (From [31]. Reproduced with permission. Olivieri NF et al. N Engl J Med. 1995;332:918-22. Copyright (C)1995 Massachusetts Medical Society. All rights reserved)

although other factors can also influence its value. There is no argument that the gold standard for iron determination is direct tissue iron determination. Notably, other methods that are becoming increasingly important include physical methods such as the superconducting quantum-interference device (SQUID) and magnetic resonance imaging (MRI).

\subsection{Direct measurement}

Liver is the major organ for iron storage and has the largest capacity to store excess iron. The measurement of hepatic iron concentration by liver biopsy is the most reliable means to assess body iron storage; however, this procedure is invasive and cannot be used in all cases [7]. Figure 2 compares the indirect estimation of body iron based on serum ferritin and LIC. Open circles denote the values at the start of the trial (before treatment with deferiprone), and solid circles denote the values at the time of the final analysis. The correlation between these measurements was significant ( $R=0.73 ; P<0.005)$ [31]. Concerning the determination of cardiac iron deposition, myocardial biopsy can be used; however, this procedure is not often conducted without special experimental reasons due to its high technical risk.

In patients with $\beta$-thalassemia, there is a correlation between LIC and cumulative amounts of RBC transfusions [26] and the risk of organ dysfunction is enhanced when LIC values are greater than $7 \mathrm{mg} / \mathrm{kg}$ wet tissue, and LIC levels of over $15 \mathrm{mg} / \mathrm{kg}$ wet tissue increase the risk of early cardiac death due to iron deposition in the myocardium [6]. Studies in the deferasirox clinical development program in $\beta$-thalassemia also demonstrated a correlation between the reduction in LIC and SF values $(R=0.63)$. 


\subsection{Physical measurement of body iron}

As iron is one of the heavy metals, an increased concentration of biological iron consisting of ferritin and hemosiderin can be detected by body imaging procedures. Until recently, abdominal echograms and computed tomography (CT) produced images at high iron concentrations, although these two modalities are not quantitative and are only capable of detecting iron overload under conditions of extremely high iron deposition [32]. Recently, quantitative procedures such as SQUID [33] and MRI have been introduced, which use the physical characteristics of iron. However, SQUID apparatus is only available in a couple of institutions in the Europe and US because of its cost. On other hand, LIC determinations by MRI are widely available. This method utilizes the specific characteristic of iron that shortens $\mathrm{T} 1, \mathrm{~T} 2$, and $\mathrm{T} 2 *$ relaxation times. The measurable range of iron concentration by $\mathrm{R} 2$ (in a $1.5-\mathrm{T}$ MRI magnet) is $0.3-42.7 \mathrm{mg} \mathrm{Fe} / \mathrm{g}$ dry tissue, which covers the concentrations observed in ironoverloaded livers.

In addition to LIC measurement, the determination of cardiac iron concentration is clinically important because one of the major causes of death in iron overload is sudden cardiac arrest. The most reliable non-invasive method of cardiac iron is MRI R2*, which was developed by Anderson et al. [34]. The advantage of MRI R2* is the shorter time period required to acquire an image as only one breath period is necessary by this procedure.

Of the patients with LIC values below $350 \mu \mathrm{mol} / \mathrm{g}$, all but one had myocardial iron within normal $(\leq 8 \mu \mathrm{mol} / \mathrm{g})$ or nearly normal ranges. When liver iron levels reached a threshold of $350 \mu \mathrm{mol} / \mathrm{g}$, iron deposition became evident in the myocardium. At the same time, there was a proportional increase in urinary iron excretion, indicating raised levels of labile iron. SF levels of $>1,800 \mu \mathrm{g} / \mathrm{L}$ were also associated with myocardial deposition.

\section{Toxic effect of iron overload on organ function}

Iron overload induces organ damage in liver, heart, pancreas, thyroid, and the central nervous system. The main cause of this organ damage is due to the overproduction of ROS in the presence of excess iron.

\subsection{Mechanism of iron toxicity}

The production of ROS by iron is mainly through the Fenton reaction, which eventually forms hydroxyl radicals from superoxide or hydrogen peroxide [35]. Among ROS, the hydroxyl radical is the most toxic fraction and it targets carbohydrate, protein, and nucleic acids. It is known that the reaction of hydroxyl radicals with the nucleic acid base 8-hydroxyguanine (8-OHG) is highly correlated with teratogenicity and carcinogenicity by oxidative stresses. Another powerful ROS showing similar reactivity as the hydroxyl radical is lipid hydroxyl-peroxide: $\mathrm{ROOH}$. In iron overload, lipid peroxidative products such as malondialdehyde and 4-hydroxy-2-nonenal are increased, which form the radicals ROO-(alkyl oxyradical) and RO-(alkoxy radical). These lipid-based radicals possess longer half lives than hydroxyl radicals, and also have a stronger capacity for chronic cell toxicity and DNA damage.

\subsection{Iron overload syndrome}

Pathological conditions representing body iron overload are designated as iron overload syndromes, and iron deposition causes organ dysfunction including cell death, fibrosis, and carcinogenesis. Iron overload syndromes are classified as genetic or secondary as shown in Table 3.

Hereditary hemochromatosis is the most common genetic disorder in Western countries [36], and its clinical

Table 3 Classification of iron overload

\begin{tabular}{|c|c|}
\hline \multicolumn{2}{|c|}{ Hereditary hemochromatosis and related disorders } \\
\hline \multirow{9}{*}{$\begin{array}{l}\text { Hereditary } \\
\text { hemochromatosis }\end{array}$} & Type 1 \\
\hline & $H F E$ gene $(6 \mathrm{p} 21.3)$ mutation \\
\hline & Type 2 \\
\hline & $\begin{array}{l}\text { Subtype A: hemojuvelin gene (1q21) } \\
\text { mutation }\end{array}$ \\
\hline & $\begin{array}{l}\text { Subtype B: hepcidin gene (19q13) } \\
\text { mutation }\end{array}$ \\
\hline & Type 3 \\
\hline & $\begin{array}{l}\text { Transferrin receptor } 2 \text { gene }(7 \mathrm{q} 22) \\
\text { mutation }\end{array}$ \\
\hline & Type 4 \\
\hline & Ferroportin gene (2q32) mutation \\
\hline Ferritin gene mutation & $\begin{array}{l}H \text {-ferritin gene mutation (mRNA iron- } \\
\text { responsive-element mutation) }\end{array}$ \\
\hline \multicolumn{2}{|l|}{$D M T 1$ gene mutation } \\
\hline \multicolumn{2}{|l|}{$\begin{array}{l}\text { Ceruloplasmin gene } \\
\text { mutation }\end{array}$} \\
\hline Atransferrinemia & Transferrin gene mutation \\
\hline \multicolumn{2}{|l|}{ Secondary iron overload } \\
\hline $\begin{array}{l}\text { Ineffective } \\
\text { erythropoiesis }\end{array}$ & $\begin{array}{l}\text { Thalassemia, sideroblastic anemia, } \\
\text { myelodysplastic syndromes }\end{array}$ \\
\hline $\begin{array}{l}\text { Administration of iron } \\
\text { for long periods }\end{array}$ & Take orally or intravenous injection \\
\hline \multicolumn{2}{|l|}{$\begin{array}{l}\text { Transfusion for long } \\
\text { periods }\end{array}$} \\
\hline \multicolumn{2}{|l|}{ Dietary iron overload } \\
\hline Liver dysfunction & $\begin{array}{l}\text { Alcoholic liver injury, chronic hepatitis } \\
\text { (type C), non-alcoholic steatohepatitis }\end{array}$ \\
\hline Others & Porphyria \\
\hline
\end{tabular}


manifestation is systemic iron deposition mainly in liver, heart, brain, and endocrine organs. This organ damage is considered to be a result of tissue injuries by iron-induced oxidative stresses [37]. In 1996, the causative gene was identified as $H F E$ in the human chromosome 6 [38], and approximately $85 \%$ of patients with hereditary hemochromatosis in Western counties have a homologous mutation of $\mathrm{C} 282 \mathrm{Y}$ in their HFE gene. Thereafter, other genes such as hemojuvelin (HJV), TfR2, ferroportin, and hepcidin (HAMP) gene were identified [39]. In spite of the lack of genetic background, iron overload is commonly observed as a secondary condition. The most common condition occurs in patients who require long-term blood transfusions due to severe anemias. This condition includes genetic disorders such as thalassemia and SCD, and anemia refractory to conventional treatments. In these patients, ineffective erythropoiesis and continuous accumulation of exogenous iron by transfusion are considered to be responsible for the iron overload. The resulting organ failures such as liver failure, cardiac failure, and severe diabetes mellitus affect patients' outcome [1]. In addition to these classical conditions, there are many diseases that show mild iron deposition or dysregulation of body iron distribution. Such conditions include chronic hepatitis C, alcoholic liver disease, non-alcoholic steatohepatitis, and insulin resistance, and iron is an important cofactor that modifies these disease conditions. Furthermore, it is becoming clear that excess iron is also hazardous as it promotes atherosclerosis, carcinogenesis, diabetes, and other lifestyle-related disorders [40].

\subsection{Organ dysfunction by excess iron}

The liver is the most important organ for iron storage with the largest capacity to sequester excess iron. The periodical change of organ dysfunction by long-term transfusions has been studied in patients with homozygous $\beta$-thalassemia. Usually, within 2 years of transfusion, abnormalities of liver function tests (LFTs) such as transaminase are not prominent; LFTs are within the normal range or slightly elevated. During these periods, the liver biopsy examination shows a slight fibrosis with mild inflammation and iron deposition. Clinically, the liver is hardened and palpable, and serum transaminase levels are moderately elevated, while other LFTs are within the normal range or slightly elevated. Therefore, it is important for transfusion-dependent patients that clinicians make a correct staging in order to confirm whether any liver lesions are fibrotic or cirrhotic by examining CT, MRI, and biochemical analyses including serum transaminase determinations.

The most important adverse event of long-term transfusion is a sudden death due to cardiac failure. It was reported that approximately $70 \%$ of deaths in patients with $\beta$-thalassemia are cardiogenic [41]. Signs of cardiac dysfunction include cardiac hypertrophy, arrhythmia, and endocarditis, which eventually cause cardiac failure. Left ventricular disturbance is prominent and is represented as the decrease of ventricular ejection fraction (VEF) by cardiac echogram. As this decrease of VEF appears prior to the clinical signs of cardiac failure and the enlargement of cardiac shadow in chest X-rays, the cardiac echogram is the most useful modality for the follow-up of myocardial damage by iron overload [42]. MRI is also useful to assess the ventricular function, and the deposition of iron in cardiac muscles is detectable by an increase in signal intensity. Furthermore, MRI calculation of $\mathrm{T} 2 *$ or R2* allows the possibility of semi-quantitation of iron concentrations, even at relatively low concentrations [43].

According to a follow-up study in patients with $\beta$-thalassemia, organ dysfunction by iron overload appears firstly in the liver when serum ferritin exceeds $1,000 \mu \mathrm{g} / \mathrm{L}$, and other organ involvements including heart follow in accordance with the further development of iron deposition. Significant cardiac iron deposition is usually observed when LICs are more than $15 \mathrm{mg} / \mathrm{g}$ dry weight or serum ferritin levels are more than 1,800-2,500 $\mu \mathrm{g} / \mathrm{L}$ [6].

Clinically, in order to detect organ dysfunctions, serum ferritin determinations should be conducted once every $1-$ 3 months. When serum ferritin levels exceed 1,500 $\mu \mathrm{g} / \mathrm{L}$, patients should be examined for the symptoms of cardiac failure or arrhythmias [44], and periodical cardiac echograms may also be useful in diagnosis.

In addition to iron deposition in the liver and heart, pancreatic beta cells are another important target of iron toxicity, which cause glucose intolerance and diabetes mellitus. An additional factor leading to the development of glucose intolerance is hepatic disturbance of insulin utilization, which accelerates beta cell depletion due to hyperinsulinemia [45]. From a clinical perspective, serial determinations of blood glucose, urine sugar, and glycoalbumin are useful, whereas glycohemoglobin is not as useful owing to the effect of transfusions. Endocrinopathies by long-term transfusion include developmental disturbances, incomplete puberty, and thyroid dysfunctions [46]. In patients with thalassemia and SCD, special attention should be paid to early onset symptoms such as disturbances of development and sexual immaturity.

\section{Conclusion}

Iron is essential for the body, but extremely toxic when excess amounts are present. As the body has no active excretion pathways for iron, a continuous load of iron exceeding 1-2 mg/day will result in iron overload, and organ failures including liver and heart. The recent 
understanding of body iron metabolism at a molecular level enables us to elucidate the mechanism of iron toxicity more precisely. Improvement of patients' outcomes is becoming promising if a correct early diagnosis is made, and suitable management of these intractable conditions using iron chelation with high compliance is conducted.

\section{References}

1. Andrews NC. Disorders of iron metabolism. N Engl J Med. 1999;341:1986-95.

2. McKie AT, Latunde-Dada GO, Miret S, et al. Molecular evidence for the role of a ferric reductase in iron transport. Biochem Soc Trans. 2002;30:722-4.

3. Trinder D, Fox C, Vautier G, Olynyk JK. Molecular pathogenesis of iron overload. Gut. 2002;51:290-5.

4. Sargent PJ, Farnaud S, Evans RW. Structure/function overview of proteins involved in iron storage and transport. Curr Med Chem. 2005;12:2683-93.

5. Cabantchik ZI, Breuer W, Zanninelli G, Cianciulli P. LPI-labile plasma iron in iron overload. Best Pract Res Clin Haematol. 2005;18:277-87.

6. Olivieri NF, Brittenham GM. Iron-chelating therapy and the treatment of thalassemia. Blood. 1997;89:739-61.

7. Angelucci E, Brittenham GM, McLaren CE, et al. Hepatic iron concentration and total body iron stores in thalassemia major. $\mathrm{N}$ Engl J Med. 2000;343:327-31.

8. Ikuta K, Zak O, Aisen P. Recycling, degradation and sensitivity to the synergistic anion of transferrin in the receptor-independent route of iron uptake by human hepatoma $(\mathrm{HuH}-7)$ cells. Int $\mathbf{J}$ Biochem Cell Biol. 2004;36:340-52.

9. Liuzzi JP, Aydemir F, Nam H, Knutson MD, Cousins RJ. Zip14 (Slc39a14) mediates non-transferrin-bound iron uptake into cells. Proc Natl Acad Sci USA. 2006;103:13612-7.

10. Schranzhofer M, Schifrer M, Cabrera JA, et al. Remodeling the regulation of iron metabolism during erythroid differentiation to ensure efficient heme biosynthesis. Blood. 2006;107:4159-67.

11. Fleming MD. The genetics of inherited sideroblastic anemias. Semin Hematol. 2002;39:270-81.

12. Park $\mathrm{CH}$, Valore EV, Waring AJ, Ganz T. Hepcidin, a urinary antimicrobial peptide synthesized in the liver. J Biol Chem. 2001;276:7806-10.

13. Inamura J, Ikuta K, Jimbo J, et al. Upregulation of hepcidin by interleukin-1beta in human hepatoma cell lines. Hepatol Res. 2005;33:198-205.

14. Ganz T. Hepcidin in iron metabolism. Curr Opin Hematol. 2004;11:251-4.

15. Bridle KR, Frazer DM, Wilkins SJ, et al. Disrupted hepcidin regulation in HFE-associated haemochromatosis and the liver as a regulator of body iron homoeostasis. Lancet. 2003;361:669-73.

16. Pietrangelo A. Hemochromatosis: an endocrine liver disease. Hepatology. 2007;46:1291-301.

17. Gardenghi S, Marongiu MF, Ramos $\mathrm{P}$, et al. Ineffective erythropoiesis in $\beta$-thalassemia is characterized by increased iron absorption mediated by down-regulation of hepcidin and upregulation of ferroportin. Blood. 2007;109:5027-35.

18. Cazzola M, Huebers HA, Sayers MH, MacPhail AP, Eng M, Finch CA. Transferrin saturation, plasma iron turnover, and transferrin uptake in normal humans. Blood. 1985;66:935-9.

19. Breuer W, Hershko C, Cabantchik ZI. The importance of nontransferrin bound iron in disorders of iron metabolism. Transfus Sci. 2000;23:185-92.
20. Koorts AM, Viljoen M. Ferritin and ferritin isoforms I: structurefunction relationships, synthesis, degradation and secretion. Arch Physiol Biochem. 2007;113:30-54.

21. Harrison PM, Arosio P. The ferritins: molecular properties, iron storage function and cellular regulation. Biochim Biophys Acta. 1996;1275:161-203.

22. Jacobs A, Beamish MR, Allison M. The measurement of circulating ferritin. J Clin Pathol. 1972;25:1003.

23. Jacobs A, Miller F, Worwood M, Beamish MR, Wardrop CA. Ferritin in the serum of normal subjects and patients with iron deficiency and iron overload. Br Med J. 1972;4:206-8.

24. Piperno A. Classification and diagnosis of iron overload. Haematologica. 1998;83:447-55.

25. Saito H, Hayashi D, Ohya T, Ohya F, Yamada H. Clinical evaluation on serum ferritin (author's transl). Rinsho Ketsueki. 1979;20:1317-25.

26. Galanello R, Piga A, Forni GL, et al. Phase II clinical evaluation of deferasirox, a once-daily oral chelating agent, in paediatric patients with $\beta$-thalassaemia major. Haematologica. 2006;91:1343-51.

27. Cappellini MD, Cohen A, Piga A, et al. A phase 3 study of deferasirox (ICL670), a once-daily oral iron chelator, in patients with beta-thalassemia. Blood. 2006;107:3455-62.

28. Jensen PD, Jensen FT, Christensen T, Eiskjaer H, Baandrup U, Nielsen JL. Evaluation of myocardial iron by magnetic resonance imaging during iron chelation therapy with deferrioxamine: indication of close relation between myocardial iron content and chelatable iron pool. Blood. 2003;101:4632-9.

29. Takatoku M, Uchiyama T, Okamoto S, et al. Retrospective nationwide survey of Japanese patients with transfusion-dependent MDS and aplastic anemia highlights the negative impact of iron overload on morbidity/mortality. Eur J Haematol. 2007;78:487-94.

30. Gattermann N. Guidelines on iron chelation therapy in patients with myelodysplastic syndromes and transfusional iron overload. Leuk Res. 2007;31(Suppl 3):S10-5.

31. Olivieri NF, Brittenham GM, Matsui D, et al. Iron-chelation therapy with oral deferiprone in patients with thalassemia major. N Engl J Med. 1995;332:918-22.

32. Long JA Jr, Doppman JL, Nienhus AW, Mills SR. Computed tomographic analysis of beta-thalassemic syndromes with hemochromatosis: pathologic findings with clinical and laboratory correlations. J Comput Assist Tomogr. 1980;4:159-65.

33. Brittenham GM, Farrell DE, Harris JW, et al. Magnetic-susceptibility measurement of human iron stores. $\mathrm{N}$ Engl J Med. 1982;307:1671-5.

34. Anderson LJ, Westwood MA, Holden S, et al. Myocardial iron clearance during reversal of siderotic cardiomyopathy with intravenous desferrioxamine: a prospective study using $\mathrm{T} 2 *$ cardiovascular magnetic resonance. $\mathrm{Br} \mathrm{J}$ Haematol. 2004;127:348-55.

35. Crichton RR, Wilmet S, Legssyer R, Ward RJ. Molecular and cellular mechanisms of iron homeostasis and toxicity in mammalian cells. J Inorg Biochem. 2002;91:9-18.

36. Yen AW, Fancher TL, Bowlus CL. Revisiting hereditary hemochromatosis: current concepts and progress. Am J Med. 2006;119:391-9.

37. Pietrangelo A. Hereditary hemochromatosis - a new look at an old disease. N Engl J Med. 2004;350:2383-97.

38. Feder JN, Gnirke A, Thomas W, et al. A novel MHC class I-like gene is mutated in patients with hereditary haemochromatosis. Nat Genet. 1996;13:399-408.

39. Franchini M. Hereditary iron overload: update on pathophysiology, diagnosis, and treatment. Am J Hematol. 2006;81:2029. 
40. Bonkovsky HL, Lambrecht RW, Shan Y. Iron as a co-morbid factor in nonhemochromatotic liver disease. Alcohol. 2003;30:137-44.

41. Zurlo MG, De Stefano P, Borgna-Pignatti C, et al. Survival and causes of death in thalassaemia major. Lancet. 1989;2:27-30.

42. McGowan JH, Cleland JG. Reliability of reporting left ventricular systolic function by echocardiography: a systematic review of 3 methods. Am Heart J. 2003;146:388-97.

43. Anderson LJ, Holden S, Davis B, et al. Cardiovascular T2-star $(\mathrm{T} 2 *)$ magnetic resonance for the early diagnosis of myocardial iron overload. Eur Heart J. 2001;22:2171-9.
44. Telfer PT, Prestcott E, Holden S, Walker M, Hoffbrand AV, Wonke B. Hepatic iron concentration combined with long-term monitoring of serum ferritin to predict complications of iron overload in thalassaemia major. Br J Haematol. 2000;110:971-7. 45. Olivieri NF. The $\beta$-thalassemias. N Engl J Med. 1999;341:99109.

46. Fung EB, Harmatz PR, Lee PD, et al. Increased prevalence of iron-overload associated endocrinopathy in thalassaemia versus sickle-cell disease. Br J Haematol. 2006;135:574-82. 